\title{
PARALLEL MOVING MECHANICAL SYSTEMS
}

\author{
Florian Ion Tiberiu Petrescu \\ Bucharest Polytechnic University, Romania \\ E-mail: petrescuflorian@yahoo.com \\ Relly Victoria Virgil Petrescu \\ Bucharest Polytechnic University, Romania \\ E-mail: petrescuvictoria@yahoo.com
}

Submission: $27 / 09 / 2013$

Revision: 02/01/2014

Accept: 10/01/2014

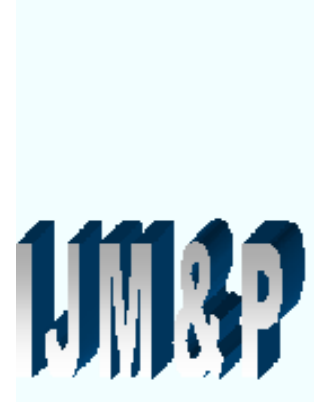

\section{ABSTRACT}

Moving mechanical systems parallel structures are solid, fast, and accurate. Between parallel systems it is to be noticed Stewart platforms, as the oldest systems, fast, solid and precise. The work outlines a few main elements of Stewart platforms. Begin with the geometry platform, kinematic elements of it, and presented then and a few items of dynamics. Dynamic primary element on it means the determination mechanism kinetic energy of the entire Stewart platforms. It is then in a record tail cinematic mobile by a method dot matrix of rotation. If a structural mottoelement consists of two moving elements which translates relative, drive train and especially dynamic it is more convenient to represent the mottoelement as a single moving components. We have thus seven moving parts (the six motoelements or feet to which is added mobile platform 7) and one fixed.

Keywords: mechatronics, robotics, a Stewart structure, parallel moving mechanical systems, direct kinematics, inverse kinematics. 
DOI: 10.14807/ijmp.v5i3.159

\section{INTRODUCTION}

Moving mechanical structures are used increasingly in almost all vital sectors of humanity (CAO et al., 2013). The robots are able to process integrated circuits sizes micro and nano, on which the man they can be seen even with electron microscopy (GARCIA et al., 2007). Dyeing parts in toxic environments (TONG; GU; XIE, 2013), working in chemical and radioactive environments, or at depths and pressures at the bottom of huge oceans, or even cosmic space conquest and visiting exo-planets, are now possible, and were turned into from the dream in reality, because mechanical platforms sequential gearbox (PERUMAAL; JAWAHAR, 2013).

Robots were developed and diversified, different aspects, but to-day, they start to be directed on two major categories: systems serial and parallel systems (PADULA; PERDEREAU, 2013). Parallel systems are more solid, but more difficult to designed and handled, which serial systems were those which have developed the most. In medical operations or radioactive environments is preferred mobile systems parallel to their high accuracy positioning (REDDY; SHIHABUDHEEN; JACOB, 2012).

\section{THE STRUCTURE AND GEOMETRY OF A STEWARD SYSTEM}

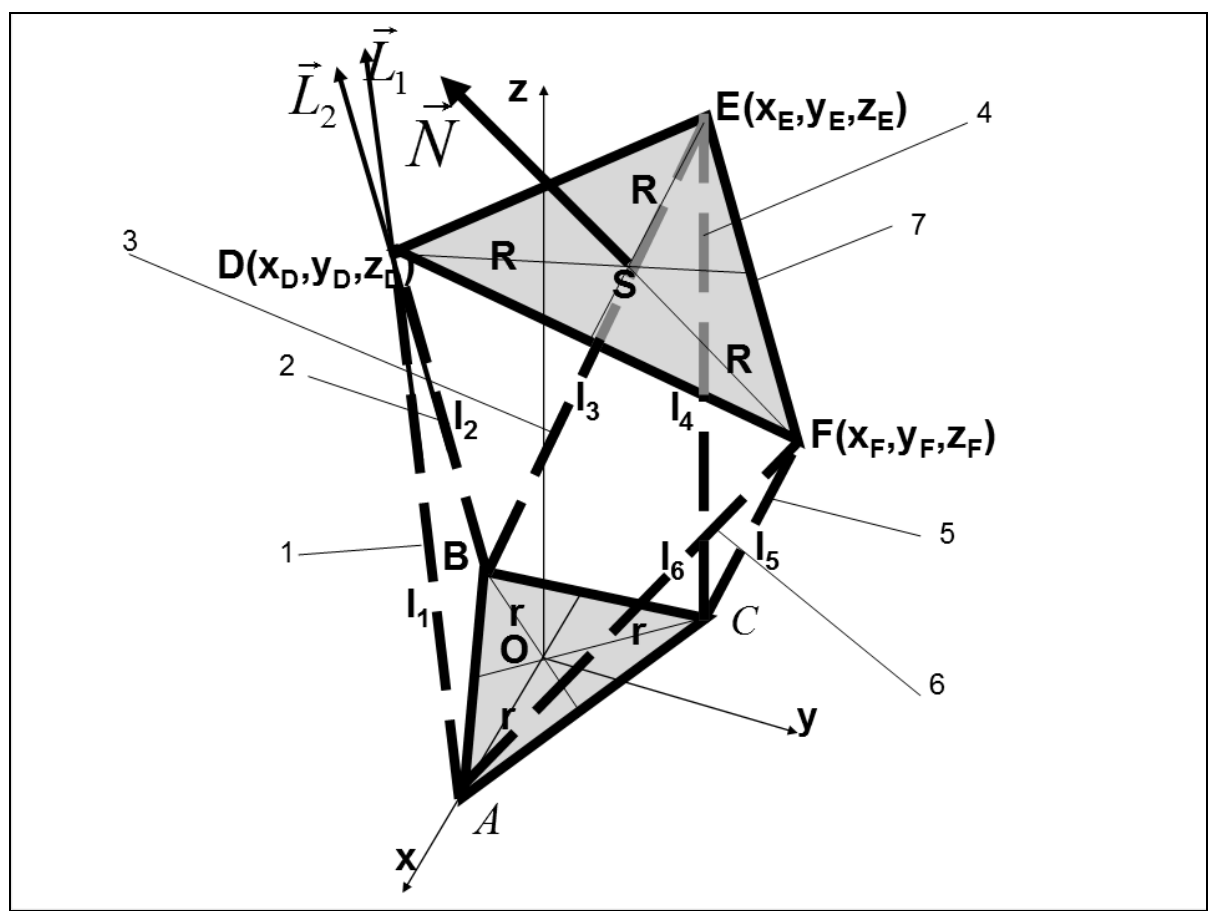

Figure 1: The basic structure of a Stewart System 
INDEPENDENT JOURNAL OF MANAGEMENT \& PRODUCTION (IJM\&P)

http://www.ijmp.jor.br

v. 5, n. 3, June - September 2014

ISSN: 2236-269X

DOI: 10.14807/ijmp.v5i3.159

Figure 1 shows unit vectors route along items 1 and 2 from the bottom to mobile platform. The co-ordinates $\left(\alpha_{i}, \beta_{i}, \gamma_{i}\right.$, system 1$)$ of vectors unit $\left(\overline{L_{i}}\right.$, system 2$)$ belonging to motto-items 1-6 (variable-length) are given by the system (1), where $\mathrm{l}_{\mathrm{i}}$ is the length (module) of vectors $\bar{l}_{i}$ (system 3); with i=1-6 (GARCIA-Murillo, 2013).

$$
\left\{\begin{array}{l}
\alpha_{1}=\frac{x_{D}-x_{A}}{l_{1}} ; \quad \beta_{1}=\frac{y_{D}-y_{A}}{l_{1}} ; \gamma_{1}=\frac{z_{D}-z_{A}}{l_{1}} ; \\
\alpha_{2}=\frac{x_{D}-x_{B}}{l_{2}} ; \quad \beta_{2}=\frac{y_{D}-y_{B}}{l_{2}} ; \gamma_{2}=\frac{z_{D}-z_{B}}{l_{2}} ; \\
\alpha_{3}=\frac{x_{E}-x_{B}}{l_{3}} ; \quad \beta_{3}=\frac{y_{E}-y_{B}}{l_{3}} ; \gamma_{3}=\frac{z_{E}-z_{B}}{l_{3}} ; \\
\alpha_{4}=\frac{x_{E}-x_{C}}{l_{4}} ; \quad \beta_{4}=\frac{y_{E}-y_{C}}{l_{4}} ; \gamma_{4}=\frac{z_{E}-z_{C}}{l_{4}} \\
\alpha_{5}=\frac{x_{F}-x_{C}}{l_{5}} ; \quad \beta_{5}=\frac{y_{F}-y_{C}}{l_{5}} ; \gamma_{5}=\frac{z_{F}-z_{C}}{l_{5}} \\
\alpha_{6}=\frac{x_{F}-x_{A}}{l_{6}} ; \quad \beta_{6}=\frac{y_{F}-y_{A}}{l_{6}} ; \gamma_{6}=\frac{z_{F}-z_{A}}{l_{6}}
\end{array}\right.
$$

Where these lengths of vectors unit are given by the system (2), and actual lengths of the six mottoelements (variables) is expressed by the system (3).

$$
\begin{cases}\bar{L}_{1}=\alpha_{1} \cdot \bar{i}+\beta_{1} \cdot \bar{j}+\gamma_{1} \cdot \bar{k} ; & \bar{L}_{2}=\alpha_{2} \cdot \bar{i}+\beta_{2} \cdot \bar{j}+\gamma_{2} \cdot \bar{k} \\ \bar{L}_{3}=\alpha_{3} \cdot \bar{i}+\beta_{3} \cdot \bar{j}+\gamma_{3} \cdot \bar{k} ; & \bar{L}_{4}=\alpha_{4} \cdot \bar{i}+\beta_{4} \cdot \bar{j}+\gamma_{4} \cdot \bar{k} \\ \bar{L}_{5}=\alpha_{5} \cdot \bar{i}+\beta_{5} \cdot \bar{j}+\gamma_{5} \cdot \bar{k} ; & \bar{L}_{6}=\alpha_{6} \cdot \bar{i}+\beta_{6} \cdot \bar{j}+\gamma_{6} \cdot \bar{k}\end{cases}
$$




$$
\left\{\begin{array}{l}
\bar{l}_{1}=l_{1} \cdot \bar{L}_{1}=\alpha_{1} \cdot l_{1} \cdot \bar{i}+\beta_{1} \cdot l_{1} \cdot \bar{j}+\gamma_{1} \cdot l_{1} \cdot \bar{k} ; \\
\bar{l}_{2}=l_{2} \cdot \bar{L}_{2}=\alpha_{2} \cdot l_{2} \cdot \bar{i}+\beta_{2} \cdot l_{2} \cdot \bar{j}+\gamma_{2} \cdot l_{2} \cdot \bar{k} \\
\bar{l}_{3}=l_{3} \cdot \bar{L}_{3}=\alpha_{3} \cdot l_{3} \cdot \bar{i}+\beta_{3} \cdot l_{3} \cdot \bar{j}+\gamma_{3} \cdot l_{3} \cdot \bar{k} ; \\
\bar{l}_{4}=l_{4} \cdot \bar{L}_{4}=\alpha_{4} \cdot l_{4} \cdot \bar{i}+\beta_{4} \cdot l_{4} \cdot \bar{j}+\gamma_{4} \cdot l_{4} \cdot \bar{k} ; \\
\bar{l}_{5}=l_{5} \cdot \bar{L}_{5}=\alpha_{5} \cdot l_{5} \cdot \bar{i}+\beta_{5} \cdot l_{5} \cdot \bar{j}+\gamma_{5} \cdot l_{5} \cdot \bar{k} ; \\
\bar{l}_{6}=l_{6} \cdot \bar{L}_{6}=\alpha_{6} \cdot l_{6} \cdot \bar{i}+\beta_{6} \cdot l_{6} \cdot \bar{j}+\gamma_{6} \cdot l_{6} \cdot \bar{k}
\end{array}\right.
$$

In Figure 2 is represented a motto element (motto element 1 ) in a position snapshots. If a structural mottoelement consists of two moving elements which translates relative, drive train and especially dynamic it is more convenient to represent the mottoelement as a single moving components. We have thus seven moving parts (the six motoelements or feet to which is added mobile platform 7) and one fixed.

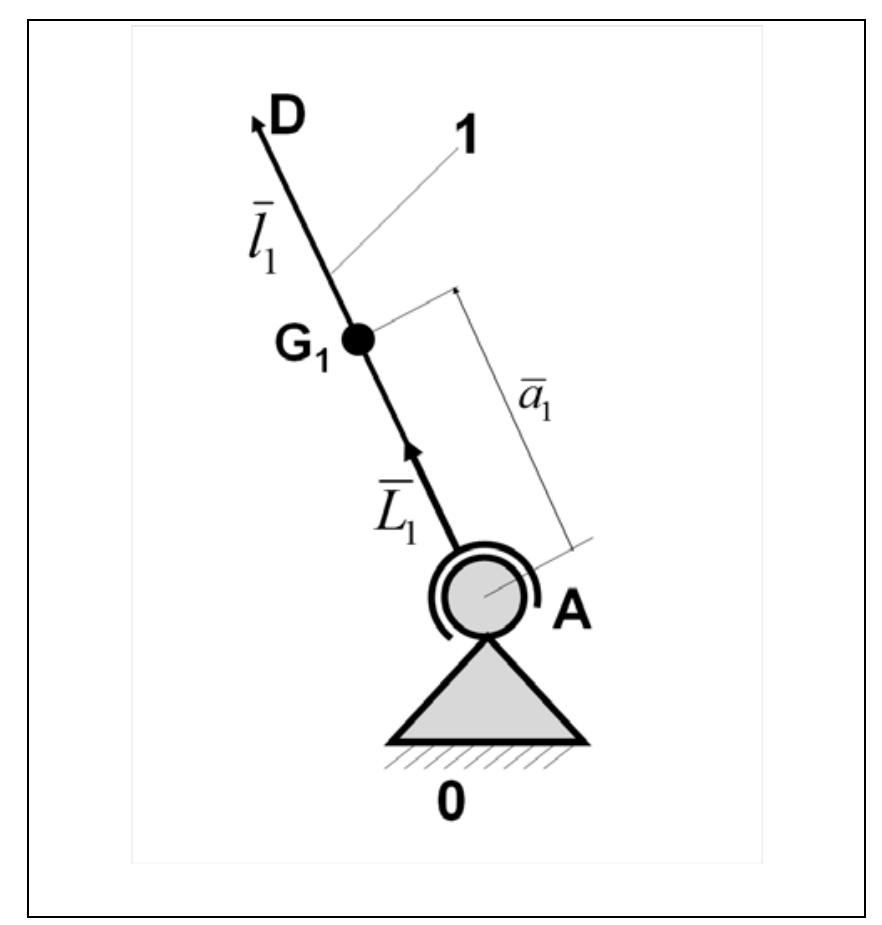

Figure 2: The basic structure of a motto element

For the stem 1 , one writes relations (4-7). The length $l_{1}=A D$ is variable $\left(\bar{l}_{1}=l_{1} \cdot \bar{L}_{1}\right)$; in the same way and the distance $a_{1}$ which defines the position of the center point of gravity $\mathrm{G}_{1}$ (and the center of gravity $\mathrm{G}_{1}$ is continuously changed, even 
INDEPENDENT JOURNAL OF MANAGEMENT \& PRODUCTION (IJM\&P)

http://www.ijmp.jor.br

v. 5, n. 3, June - September 2014

ISSN: 2236-269X

DOI: 10.14807/ijmp.v5i3.159

if rod mass formed from virtually two kinematic elements in relative movement of translation is virtually constant).

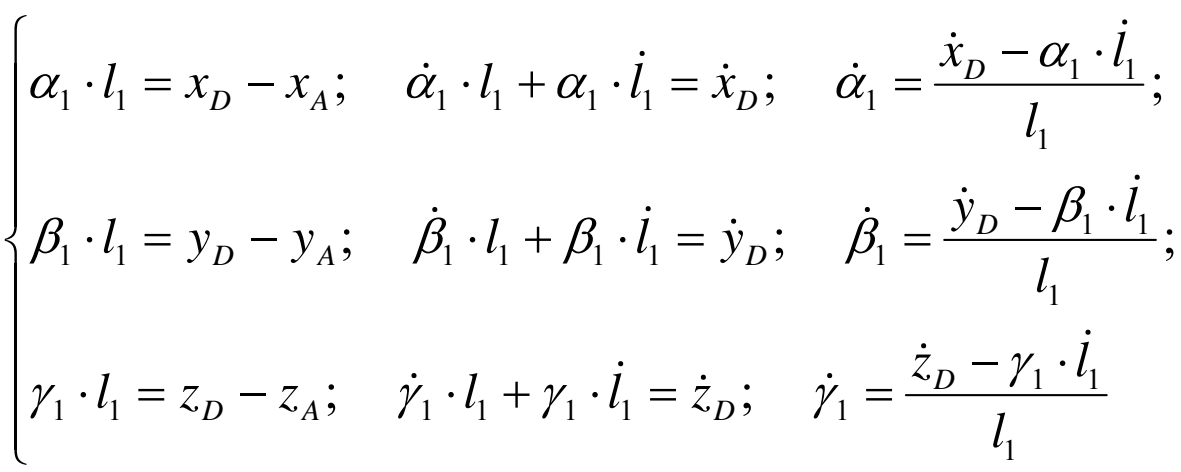

$$
\begin{aligned}
& \left\{\begin{array}{l}
x_{D}=x_{A}+\alpha_{1} \cdot l_{1} ; \quad y_{D}=y_{A}+\beta_{1} \cdot l_{1} ; \quad z_{D}=z_{A}+\gamma_{1} \cdot l_{1} ; \\
x_{G_{1}}=x_{A}+\alpha_{1} \cdot a_{1} ; \quad y_{G_{1}}=y_{A}+\beta_{1} \cdot a_{1} ; \quad z_{G_{1}}=z_{A}+\gamma_{1} \cdot a_{1}
\end{array}\right. \\
& \left\{\begin{array}{l}
x_{G_{1}}=\frac{a_{1} \cdot x_{D}+\left(l_{1}-a_{1}\right) \cdot x_{A}}{l_{1}} \\
y_{G_{1}}=\frac{a_{1} \cdot y_{D}+\left(l_{1}-a_{1}\right) \cdot y_{A}}{l_{1}} \\
z_{G_{1}}=\frac{a_{1} \cdot z_{D}+\left(l_{1}-a_{1}\right) \cdot z_{A}}{l_{1}}
\end{array}\right. \\
& \left\{\begin{array}{l}
l_{1} \cdot x_{G_{1}}=a_{1} \cdot x_{D}+\left(l_{1}-a_{1}\right) \cdot x_{A} ; \dot{l}_{1} \cdot x_{G_{1}}+l_{1} \cdot \dot{x}_{G_{1}}= \\
=\dot{a}_{1} \cdot x_{D}+a_{1} \cdot \dot{x}_{D}+\left(i_{1}-\dot{a}_{1}\right) \cdot x_{A} ; \\
\dot{x}_{G_{1}}=\frac{\dot{a}_{1} \cdot x_{D}+a_{1} \cdot \dot{x}_{D}-i_{1} \cdot x_{G_{1}}+\left(i_{1}-\dot{a}_{1}\right) \cdot x_{A}}{l_{1}} ; \\
\dot{y}_{G_{1}}=\frac{\dot{a}_{1} \cdot y_{D}+a_{1} \cdot \dot{y}_{D}-\dot{l}_{1} \cdot y_{G_{1}}+\left(l_{1}-\dot{a}_{1}\right) \cdot y_{A}}{l_{1}} ; \\
\dot{z}_{G_{1}}=\frac{\dot{a}_{1} \cdot z_{D}+a_{1} \cdot \dot{z}_{D}-\dot{l}_{1} \cdot z_{G_{1}}+\left(i_{1}-\dot{a}_{1}\right) \cdot z_{A}}{l_{1}}
\end{array}\right.
\end{aligned}
$$

Kinetic energy of the mechanism (8) is being written while taking account of the fact that the translation center of gravity of each mottoelement already contains and the effect of different rotations. Each motoelement (rod) will be studied as a single kinematic element variable-length to constant mass and the position of the center of gravity variable. Each mottoelement movement is one of spatial rotation (PETRESCU et al., 2009; PETRESCU; PETRESCU, 2011-2013). 


$$
\left\{\begin{array}{l}
E_{c}=\frac{m_{1}}{2} \cdot\left(\dot{x}_{G_{1}}^{2}+\dot{y}_{G_{1}}^{2}+\dot{z}_{G_{1}}^{2}\right)+\frac{m_{2}}{2} \cdot\left(\dot{x}_{G_{2}}^{2}+\dot{y}_{G_{2}}^{2}+\dot{z}_{G_{2}}^{2}\right)+\frac{m_{3}}{2} \cdot\left(\dot{x}_{G_{3}}^{2}+\dot{y}_{G_{3}}^{2}+\dot{z}_{G_{3}}^{2}\right)+ \\
+\frac{m_{4}}{2} \cdot\left(\dot{x}_{G_{4}}^{2}+\dot{y}_{G_{4}}^{2}+\dot{z}_{G_{4}}^{2}\right)+\frac{m_{5}}{2} \cdot\left(\dot{x}_{G_{5}}^{2}+\dot{y}_{G_{5}}^{2}+\dot{z}_{G_{5}}^{2}\right)+\frac{m_{6}}{2} \cdot\left(\dot{x}_{G_{6}}^{2}+\dot{y}_{G_{6}}^{2}+\dot{z}_{G_{6}}^{2}\right)+ \\
+\frac{m_{7}}{2} \cdot\left(\dot{x}_{S}^{2}+\dot{y}_{S}^{2}+\dot{z}_{S}^{2}\right)+\frac{J_{7 S N}}{2} \cdot \omega_{7 S N}^{2}
\end{array}\right.
$$

After the model system (7) is determined velocities of centers of the weight of the six rods (see equations 9). Speeds $\dot{x}_{S}, \dot{y}_{S}, \dot{z}_{S}, \omega_{7 S N}$ are known. The masses are weighed and mass moment of inertia after axis $\mathrm{N}$ shall be calculated on the basis of a approximate formula (10).

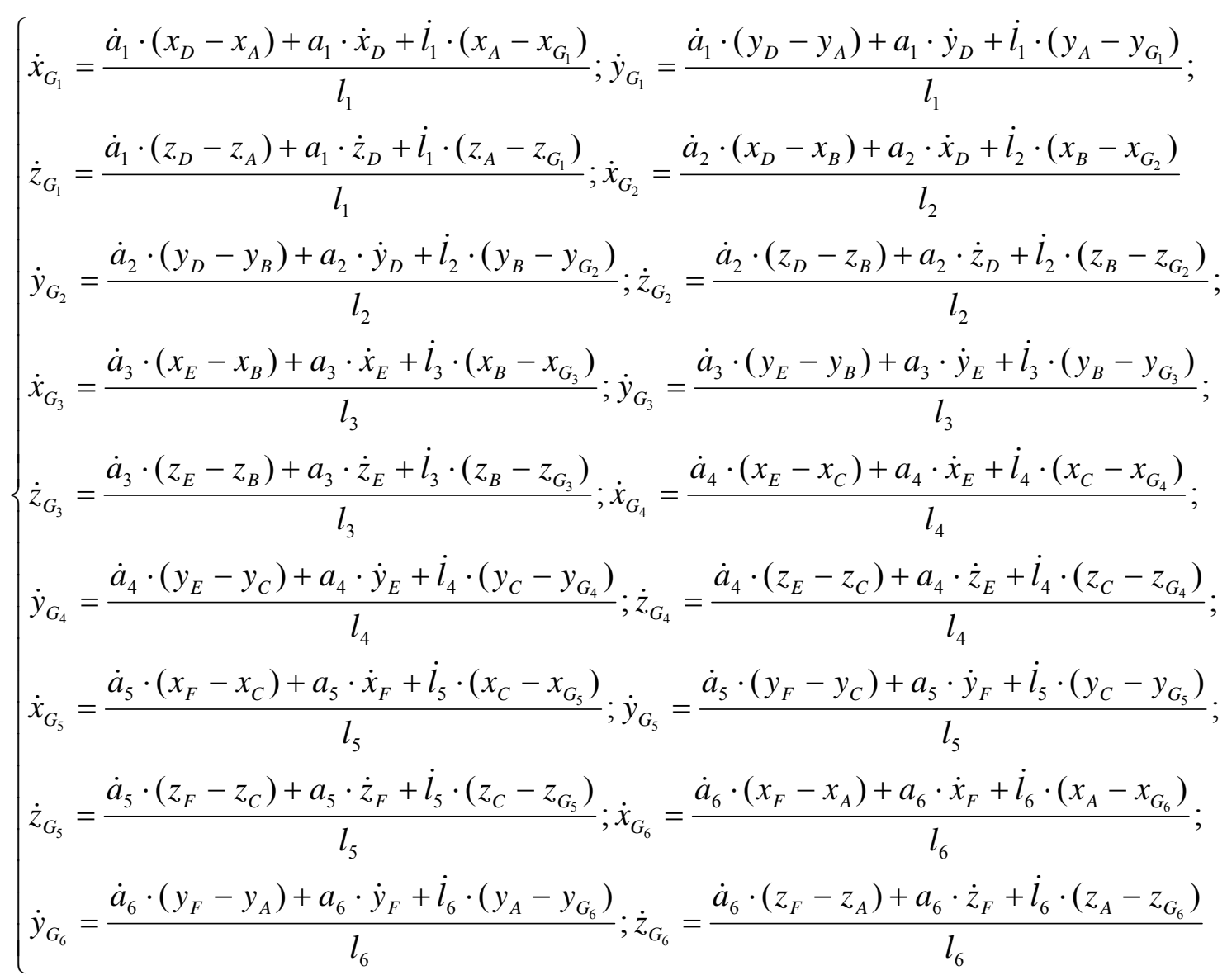




$$
\begin{aligned}
& J_{7 S N}=\frac{\frac{1}{2} m_{p} \cdot R_{T}^{2}+\frac{1}{2} m_{p} \cdot r_{T}^{2}}{2}=\frac{m_{p}}{4} \cdot\left(R_{T}^{2}+r_{T}^{2}\right)=\frac{m_{p}}{4} \cdot\left[R_{T}^{2}+\left(\frac{1}{2} R_{T}\right)^{2}\right]= \\
& =\frac{m_{p}}{4} \cdot R_{T}^{2} \cdot\left(1+\frac{1}{4}\right)=\frac{5}{16} \cdot m_{p} \cdot R_{T}^{2}=\frac{5}{16} \cdot m_{p} \cdot R^{2}
\end{aligned}
$$

Where mp shall mean the mass mobile tray 7 (obtained by weighing).

\section{THE GEOMETRY AND CINEMATIC OF MOBILE TRAY 7, BY A MATRIX ROTATION METHOD}

In Figure 3 is represented mobile plate 7, consisting of an equilateral triangle DEF with the center $S$. Attach this triangle a system of axs rectangular, mobile, jointly and severally liable with the platform, $x_{1} S y_{1} z_{1}$ (LIU et al., 2013).

Known vector $\bar{N}$ coordinates and the coordinates of the pixel $S$ (in relation with the fixed mark considered initially, linked to the fixed platform, be taken as the basis); we know so the co-ordinates of rectangular axis $\mathrm{Sz}_{1}$, in such a way that can be calculated for a start axis coordinates $\mathrm{Sx}_{1}$ (relations 11 ), axis determined by points $S, D$ (known). The co-ordinates are obtained vector $S x_{1}$. This, along with the coordinates of the pixel $S$ causes axis $S x_{1}$ (11) (PETRESCU et al., 2009; PETRESCU; PETRESCU, 2011-2013).

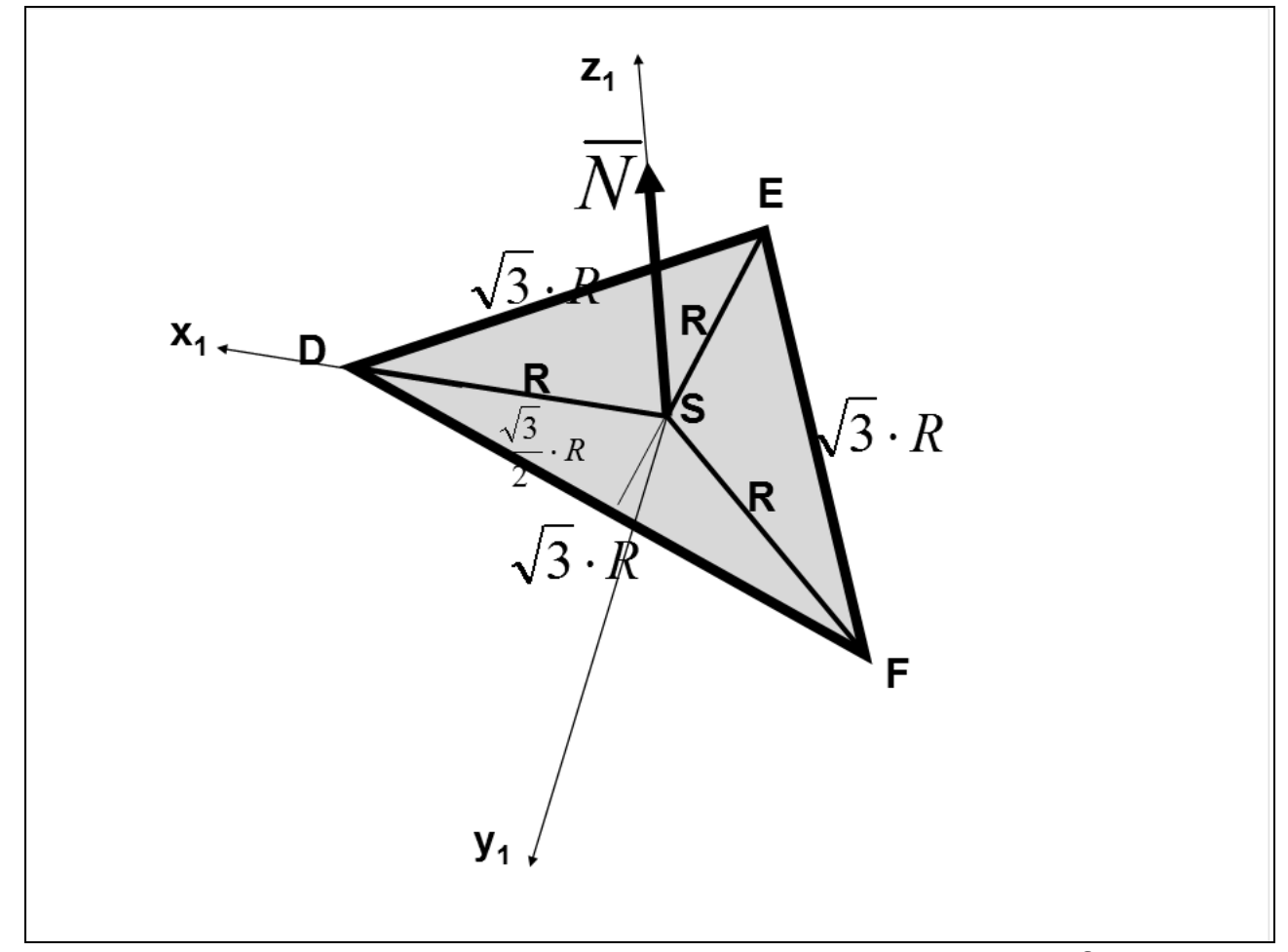

Figure 3: The geometry and kinematics mobile platform 7 
INDEPENDENT JOURNAL OF MANAGEMENT \& PRODUCTION (IJM\&P)

http://www.ijmp.jor.br

v. 5, n. 3, June - September 2014

ISSN: 2236-269X

DOI: 10.14807/ijmp.v5i3.159

$$
\left\{\begin{array}{l}
l_{S D}=\sqrt{\left(x_{D}-x_{S}\right)^{2}+\left(y_{D}-y_{S}\right)^{2}+\left(z_{D}-z_{S}\right)^{2}}= \\
=\sqrt{R^{2}}=R ; \quad \alpha_{x_{1}}=\frac{x_{D}-x_{S}}{l_{S D}}=\frac{x_{D}-x_{S}}{R} ; \\
\beta_{x_{1}}=\frac{y_{D}-y_{S}}{l_{S D}}=\frac{y_{D}-y_{S}}{R} ; \quad \gamma_{x_{1}}=\frac{z_{D}-z_{S}}{l_{S D}}=\frac{z_{D}-z_{S}}{R}
\end{array}\right.
$$

By screwing axis $\overrightarrow{S z_{1}}$ by (over) axis $\overrightarrow{S x_{1}}$, weve axis $\overrightarrow{S y_{1}}(12)$. The co-ordinates are thus obtained mobile system $\mathrm{x}_{1} \mathrm{Sy}_{1} \mathrm{z}_{1}(12)$.

$$
\begin{aligned}
& \left\{\begin{array}{l}
\overrightarrow{S y_{1}}=\overrightarrow{S z_{1}} \times \overrightarrow{S x_{1}}=\left|\begin{array}{ccc}
\bar{i} & \bar{j} & \bar{k} \\
\alpha & \beta & \gamma \\
\alpha_{x_{1}} & \beta_{x_{1}} & \gamma_{x_{1}}
\end{array}\right|= \\
=\left(\beta \cdot \gamma_{x_{1}}-\beta_{x_{1}} \cdot \gamma\right) \cdot \bar{i}+\left(\alpha_{x_{1}} \cdot \gamma-\alpha \cdot \gamma_{x_{1}}\right) \cdot \bar{j}+\left(\alpha \cdot \beta_{x_{1}}-\alpha_{x_{1}} \cdot \beta\right) \cdot \bar{k}= \\
=\frac{\beta \cdot\left(z_{D}-z_{S}\right)-\gamma \cdot\left(y_{D}-y_{S}\right)}{R} \cdot \bar{i}+\frac{\gamma \cdot\left(x_{D}-x_{S}\right)-\alpha \cdot\left(z_{D}-z_{S}\right)}{R} \cdot \bar{j}+ \\
+\frac{\alpha \cdot\left(y_{D}-y_{S}\right)-\beta \cdot\left(x_{D}-x_{S}\right)}{R} \cdot \bar{k}=\alpha_{y_{1}} \cdot \bar{i}+\beta_{y_{1}} \cdot \bar{j}+\gamma_{y_{1}} \cdot \bar{k} ; \\
\alpha_{y_{1}}=\frac{\beta \cdot\left(z_{D}-z_{S}\right)-\gamma \cdot\left(y_{D}-y_{S}\right)}{R} ; \quad \Rightarrow\left|\begin{array}{lll}
\alpha_{x_{1}} & \beta_{x_{1}} & \gamma_{x_{1}} \\
\alpha_{y_{1}} & \beta_{y_{1}} & \gamma_{y_{1}} \\
\alpha & \beta & \gamma
\end{array}\right| \\
\beta_{y_{1}}=\frac{\gamma \cdot\left(x_{D}-x_{S}\right)-\alpha \cdot\left(z_{D}-z_{S}\right)}{R} ; \quad \Rightarrow\left[x_{1} z_{1} z_{1}\right]
\end{array}\right. \\
& \gamma_{y_{1}}=\frac{\alpha \cdot\left(y_{D}-y_{S}\right)-\beta \cdot\left(x_{D}-x_{S}\right)}{R} ; \\
& \alpha_{x_{1}}=\frac{x_{D}-x_{S}}{R} ; \quad \alpha_{y_{1}}=\frac{\beta \cdot\left(z_{D}-z_{S}\right)-\gamma \cdot\left(y_{D}-y_{S}\right)}{R} ; \alpha_{z_{1}}=\alpha ; \\
& \beta_{x_{1}}=\frac{y_{D}-y_{S}}{R} ; \quad \beta_{y_{1}}=\frac{\gamma \cdot\left(x_{D}-x_{S}\right)-\alpha \cdot\left(z_{D}-z_{S}\right)}{R} ; \beta_{z_{1}}=\beta ; \\
& \gamma_{x_{1}}=\frac{z_{D}-z_{S}}{R} ; \gamma_{y_{1}}=\frac{\alpha \cdot\left(y_{D}-y_{S}\right)-\beta \cdot\left(x_{D}-x_{S}\right)}{R} ; \gamma_{z_{1}}=\gamma
\end{aligned}
$$

In Figure 4 is given a positive rotation to axis $\overrightarrow{S x_{1}}$ around the axis $\overrightarrow{S z_{1}}(\bar{N})$, the angle $\varphi_{1}$. 


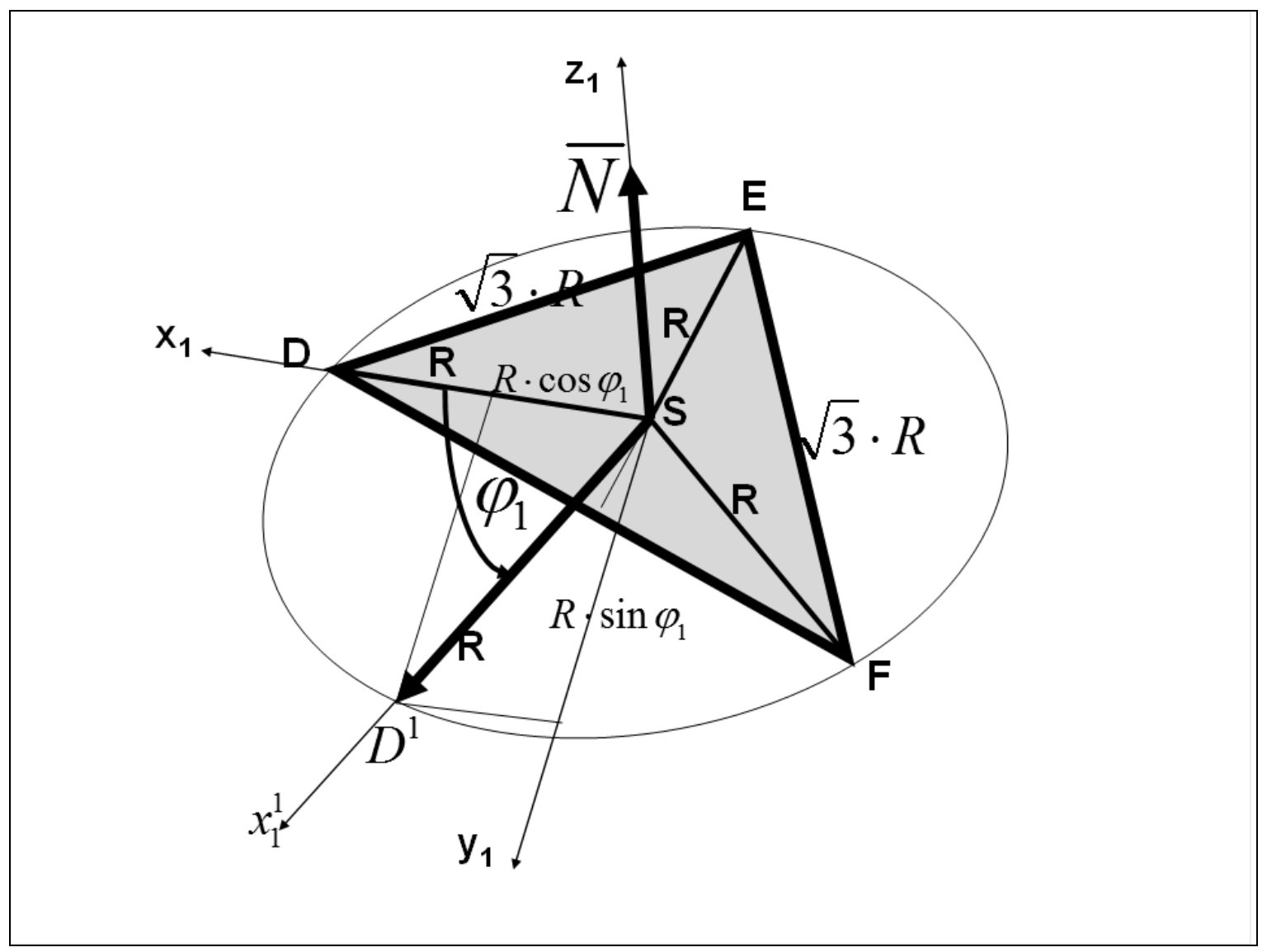

Figure 4. Rotation around the axis $\mathrm{N}$ (within mobile platform)

Using relations (13) to be written about the system matrix (14), which is determined directly (using rotation matrix) absolute co-ordinates (in accordance with the mark fixed cartesian) of a point $D^{1}$ that is part of the plan of mobile top plate. This point moves on the circle of radius $R$ and center $S$ in accordance with rotation imposed by the rotation angle $\varphi_{1}$. Final coordinates are explained in the form (15) (PETRESCU et al., 2009; PETRESCU; PETRESCU, 2011-2013).

$$
\begin{aligned}
& \left(\alpha_{x_{1}}=\frac{x_{D}-x_{S}}{R} ; \quad \alpha_{y_{1}}=\frac{\beta \cdot\left(z_{D}-z_{S}\right)-\gamma \cdot\left(y_{D}-y_{S}\right)}{R} ; \quad \alpha_{z_{1}}=\alpha ; x_{1 D^{1}}=R \cdot \cos \varphi_{1}\right. \\
& \left\{\beta_{x_{1}}=\frac{y_{D}-y_{S}}{R} ; \quad \beta_{y_{1}}=\frac{\gamma \cdot\left(x_{D}-x_{S}\right)-\alpha \cdot\left(z_{D}-z_{S}\right)}{R} ; \beta_{z_{1}}=\beta ; y_{1 D^{1}}=R \cdot \sin \varphi_{1}\right. \\
& \gamma_{x_{1}}=\frac{z_{D}-z_{S}}{R} ; \quad \gamma_{y_{1}}=\frac{\alpha \cdot\left(y_{D}-y_{S}\right)-\beta \cdot\left(x_{D}-x_{S}\right)}{R} ; \gamma_{z_{1}}=\gamma ; z_{1 D^{1}}=0
\end{aligned}
$$


$\left\{\begin{array}{l}{\left[\begin{array}{l}x_{D^{1}} \\ y_{D^{1}} \\ z_{D^{1}}\end{array}\right]=\left[\begin{array}{l}x_{S} \\ y_{S} \\ z_{S}\end{array}\right]+\left|\begin{array}{lll}\alpha_{x_{1}} & \beta_{x_{1}} & \gamma_{x_{1}} \\ \alpha_{y_{1}} & \beta_{y_{1}} & \gamma_{y_{1}} \\ \alpha_{z_{1}} & \beta_{z_{1}} & \gamma_{z_{1}}\end{array}\right| \cdot\left[\begin{array}{l}x_{1 D^{1}} \\ y_{1 D^{1}} \\ z_{1 D^{1}}\end{array}\right]=\left[\begin{array}{l}x_{S}+\alpha_{x_{1}} \cdot x_{1 D^{1}}+\beta_{x_{1}} \cdot y_{1 D^{1}}+\gamma_{x_{1}} \cdot z_{1 D^{1}} \\ y_{S}+\alpha_{y_{1}} \cdot x_{1 D^{1}}+\beta_{y_{1}} \cdot y_{1 D^{1}}+\gamma_{y_{1}} \cdot z_{1 D^{1}} \\ z_{S}+\alpha_{z_{1}} \cdot x_{1 D^{1}}+\beta_{z_{1}} \cdot y_{1 D^{1}}+\gamma_{z_{1}} \cdot z_{1 D^{1}}\end{array}\right]=} \\ =\left[\begin{array}{l}x_{S}+\left(x_{D}-x_{S}\right) \cdot \cos \varphi_{1}+\left(y_{D}-y_{S}\right) \cdot \sin \varphi_{1} \\ y_{S}+\left[\beta \cdot\left(z_{D}-z_{S}\right)-\gamma \cdot\left(y_{D}-y_{S}\right)\right] \cdot \cos \varphi_{1}+\left[\gamma \cdot\left(x_{D}-x_{S}\right)-\alpha \cdot\left(z_{D}-z_{S}\right)\right] \cdot \sin \varphi_{1} \\ z_{S}+\alpha \cdot R \cdot \cos \varphi_{1}+\beta \cdot R \cdot \sin \varphi_{1}\end{array}\right]\end{array}\right.$

$\left\{\begin{array}{l}x_{D^{1}}=x_{S}+\left(x_{D}-x_{S}\right) \cdot \cos \varphi_{1}+\left(y_{D}-y_{S}\right) \cdot \sin \varphi_{1} \\ y_{D^{1}}=y_{S}+\left[\beta \cdot\left(z_{D}-z_{S}\right)-\gamma \cdot\left(y_{D}-y_{S}\right)\right] \cos \varphi_{1}+\left[\gamma \cdot\left(x_{D}-x_{S}\right)-\alpha \cdot\left(z_{D}-z_{S}\right)\right] \sin \varphi_{1} \\ z_{D^{1}}=z_{S}+\alpha \cdot R \cdot \cos \varphi_{1}+\beta \cdot R \cdot \sin \varphi_{1}\end{array}\right.$

Rotation matrix method is used to obtain the point $F$ (for a deduction point coordinates $F$ ). Point $D$ shall be superimposed over the point $F$, if assigns to point $D$ a positive rotation of $120^{\circ}$ (relations 16-17). Derive the system (17) and we obtain directly velocities (18) and accelerations (19) of the point F (HE et al., 2013).

$$
\left\{\begin{array}{l}
x_{F}=x_{D_{120}^{1}}=x_{S}+\left(x_{D}-x_{S}\right) \cdot \cos 120+\left(y_{D}-y_{S}\right) \cdot \sin 120 \\
y_{F}=y_{D_{120}^{1}}=y_{S}+\left[\beta \cdot\left(z_{D}-z_{S}\right)-\gamma \cdot\left(y_{D}-y_{S}\right)\right] \cdot \cos 120+ \\
+\left[\gamma \cdot\left(x_{D}-x_{S}\right)-\alpha \cdot\left(z_{D}-z_{S}\right)\right] \cdot \sin 120 \\
z_{F}=z_{D_{120}^{1}}=z_{S}+\alpha \cdot R \cdot \cos 120+\beta \cdot R \cdot \sin 120
\end{array}\right.
$$

$$
\left\{\begin{array}{l}
x_{F}=x_{S}-\frac{1}{2} \cdot\left(x_{D}-x_{S}\right)+\frac{\sqrt{3}}{2} \cdot\left(y_{D}-y_{S}\right) \\
y_{F}=y_{S}-\frac{1}{2} \cdot\left[\beta \cdot\left(z_{D}-z_{S}\right)-\gamma \cdot\left(y_{D}-y_{S}\right)\right]+ \\
+\frac{\sqrt{3}}{2} \cdot\left[\gamma \cdot\left(x_{D}-x_{S}\right)-\alpha \cdot\left(z_{D}-z_{S}\right)\right] \\
z_{F}=z_{S}-\frac{1}{2} \cdot R \cdot \alpha+\frac{\sqrt{3}}{2} \cdot R \cdot \beta
\end{array}\right.
$$




$$
\left\{\begin{array}{l}
\left\{\begin{array}{l}
\dot{x}_{F}=\dot{x}_{S}-\frac{1}{2} \cdot\left(\dot{x}_{D}-\dot{x}_{S}\right)+\frac{\sqrt{3}}{2} \cdot\left(\dot{y}_{D}-\dot{y}_{S}\right) \\
\dot{y}_{F}=\dot{y}_{S}-\frac{1}{2} \cdot\left[\dot{\beta} \cdot\left(z_{D}-z_{S}\right)+\beta \cdot\left(\dot{z}_{D}-\dot{z}_{S}\right)-\dot{\gamma} \cdot\left(y_{D}-y_{S}\right)-\gamma \cdot\left(\dot{y}_{D}-\dot{y}_{S}\right)\right]+ \\
+\frac{\sqrt{3}}{2} \cdot\left[\dot{\gamma} \cdot\left(x_{D}-x_{S}\right)+\gamma \cdot\left(\dot{x}_{D}-\dot{x}_{S}\right)-\dot{\alpha} \cdot\left(z_{D}-z_{S}\right)-\alpha \cdot\left(\dot{z}_{D}-\dot{z}_{S}\right)\right] \\
\dot{z}_{F}=\dot{z}_{S}-\frac{1}{2} \cdot R \cdot \dot{\alpha}+\frac{\sqrt{3}}{2} \cdot R \cdot \dot{\beta} \\
\ddot{y}_{F}=\ddot{y}_{S}-\frac{1}{2} \cdot\left[\ddot{\beta} \cdot\left(z_{D}-z_{S}\right)+2 \cdot \dot{\beta} \cdot\left(\dot{z}_{D}-\dot{z}_{S}\right)+\beta \cdot\left(\ddot{z}_{D}-\ddot{z}_{S}\right)-\right. \\
\left.-\ddot{\gamma} \cdot\left(y_{D}-y_{S}\right)-2 \cdot \dot{\gamma} \cdot\left(\dot{y}_{D}-\dot{y}_{S}\right)-\gamma \cdot\left(\ddot{y}_{D}-\ddot{y}_{S}\right)\right]+ \\
+\frac{\sqrt{3}}{2} \cdot\left(\ddot{\gamma} \cdot\left(x_{D}-x_{S}\right)+2 \cdot \dot{\gamma} \cdot\left(\dot{x}_{D}-\dot{x}_{S}\right)+\gamma \cdot\left(\ddot{x}_{D}-\ddot{x}_{S}\right)-\right. \\
\left.-\ddot{\alpha} \cdot\left(z_{D}-z_{S}\right)-2 \cdot \dot{\alpha} \cdot\left(\dot{z}_{D}-\dot{z}_{S}\right)-\alpha \cdot\left(\ddot{z}_{D}-\ddot{z}_{S}\right)\right] \\
\ddot{z}_{F}=\ddot{z}_{S}-\frac{1}{2} \cdot R \cdot \ddot{\alpha}+\frac{\sqrt{3}}{2} \cdot R \cdot \ddot{\beta}
\end{array}\right.
\end{array}\right.
$$

For the purpose of determining point coordinates E're still circling the point $\mathrm{D}$ with $\varphi_{1}=-120^{\circ}(20)$. Velocities (21) and accelerations (22) point $\mathrm{E}$ is determined by deriving system (20) (LEE, 2013).

$$
\left\{\begin{array}{l}
x_{E}=x_{S}-\frac{1}{2} \cdot\left(x_{D}-x_{S}\right)-\frac{\sqrt{3}}{2} \cdot\left(y_{D}-y_{S}\right) \\
y_{E}=y_{S}-\frac{1}{2} \cdot\left[\beta \cdot\left(z_{D}-z_{S}\right)-\gamma \cdot\left(y_{D}-y_{S}\right)\right]- \\
-\frac{\sqrt{3}}{2} \cdot\left[\gamma \cdot\left(x_{D}-x_{S}\right)-\alpha \cdot\left(z_{D}-z_{S}\right)\right] \\
z_{E}=z_{S}-\frac{1}{2} \cdot R \cdot \alpha-\frac{\sqrt{3}}{2} \cdot R \cdot \beta
\end{array}\right.
$$


INDEPENDENT JOURNAL OF MANAGEMENT \& PRODUCTION (IJM\&P)

http://www.ijmp.jor.br

v. 5, n. 3, June - September 2014 ISSN: 2236-269X

DOI: 10.14807/ijmp.v5i3.159

$$
\left\{\begin{array}{l}
\dot{x}_{E}=\dot{x}_{S}-\frac{1}{2} \cdot\left(\dot{x}_{D}-\dot{x}_{S}\right)-\frac{\sqrt{3}}{2} \cdot\left(\dot{y}_{D}-\dot{y}_{S}\right) \\
\dot{y}_{E}=\dot{y}_{S}-\frac{1}{2} \cdot\left[\dot{\beta} \cdot\left(z_{D}-z_{S}\right)+\beta \cdot\left(\dot{z}_{D}-\dot{z}_{S}\right)-\dot{\gamma} \cdot\left(y_{D}-y_{S}\right)-\gamma \cdot\left(\dot{y}_{D}-\dot{y}_{S}\right)\right]- \\
-\frac{\sqrt{3}}{2} \cdot\left[\dot{\gamma} \cdot\left(x_{D}-x_{S}\right)+\gamma \cdot\left(\dot{x}_{D}-\dot{x}_{S}\right)-\dot{\alpha} \cdot\left(z_{D}-z_{S}\right)-\alpha \cdot\left(\dot{z}_{D}-\dot{z}_{S}\right)\right] \\
\dot{z}_{E}=\dot{z}_{S}-\frac{1}{2} \cdot R \cdot \dot{\alpha}-\frac{\sqrt{3}}{2} \cdot R \cdot \dot{\beta} \\
\ddot{x}_{E}=\ddot{y}_{S}-\frac{1}{2} \cdot\left[\ddot{\beta} \cdot\left(z_{D}-z_{S}\right)+2 \cdot \dot{\beta} \cdot\left(\dot{z}_{D}-\dot{z}_{S}\right)+\beta \cdot\left(\ddot{z}_{D}-\ddot{z}_{S}\right)-\right. \\
\left.-\ddot{\gamma} \cdot\left(y_{D}-y_{S}\right)-2 \cdot \dot{\gamma} \cdot\left(\dot{y}_{D}-\dot{y}_{S}\right)-\gamma \cdot\left(\ddot{y}_{D}-\ddot{y}_{S}\right)\right]- \\
-\frac{\sqrt{3}}{2} \cdot\left[\ddot{\gamma} \cdot\left(x_{D}-x_{S}\right)+2 \cdot \dot{\gamma} \cdot\left(\dot{x}_{D}-\dot{x}_{S}\right)+\gamma \cdot\left(\ddot{x}_{D}-\ddot{x}_{S}\right)-\right. \\
\left.-\ddot{\alpha} \cdot\left(z_{D}-z_{S}\right)-2 \cdot \dot{\alpha} \cdot\left(\dot{z}_{D}-\dot{z}_{S}\right)-\alpha \cdot\left(\ddot{z}_{D}-\ddot{z}_{S}\right)\right] \\
\ddot{z}
\end{array}\right.
$$

\section{APPLICATIONS}

Presented system can be useful in particular to the surgical robot that operate patients who require an accuracy of positioning very high (see figure 5).

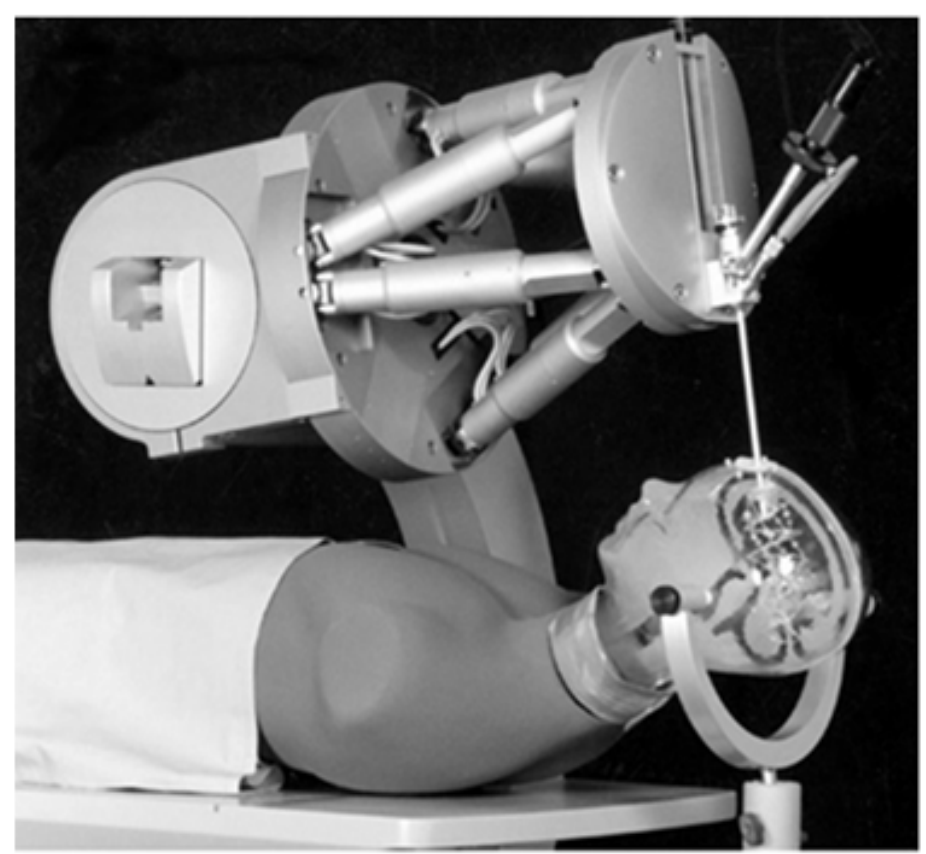

Figure 5: Surgical robot that operate patients who require an accuracy of positioning very high 
INDEPENDENT JOURNAL OF MANAGEMENT \& PRODUCTION (IJM\&P)

http://www.ijmp.jor.br

v. 5, n. 3, June - September 2014

ISSN: 2236-269X

DOI: 10.14807/ijmp.v5i3.159

These platforms can position very accurately even very large weights, such as a telescope modern stationary (see Fig. 6).

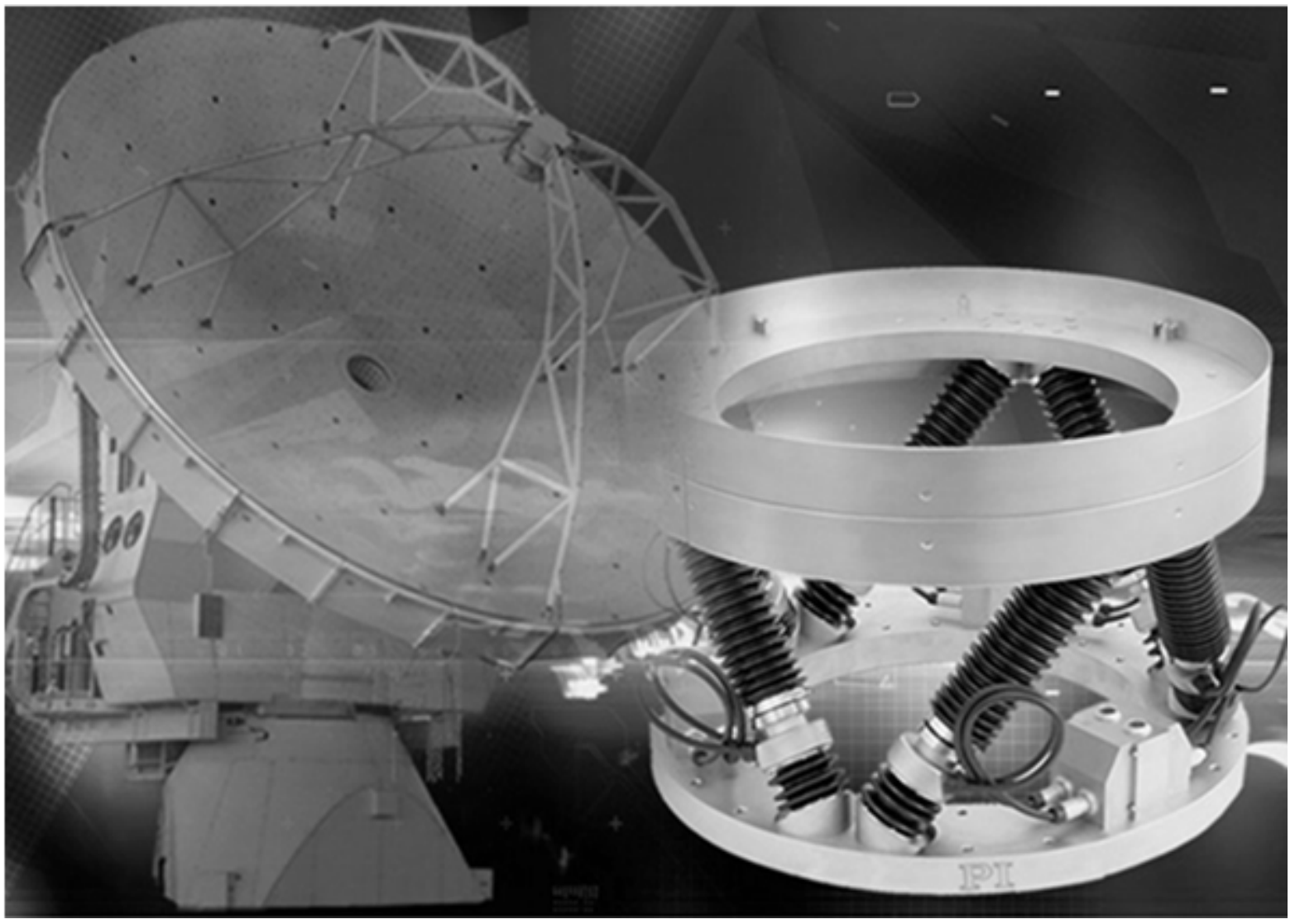

Figure 6: A modern stationary telescope positioned by a Stewart system

Other applications of the platform Stewart are handling and precise positioning of objects large and heavy.

Spatial Stewart platforms may conquer outer space in the future (MELO; ALVES; ROSÁRIO, 2012).

The latest PC-based digital controllers, facilitated by open-interface architecture providing a variety of high-level commands, allow choosing any point in space as the pivot point for the rotation axes by software command (TANG; SUN; SHAO, 2013). Target positions in 6-space are specified in Cartesian coordinates, and the controller transforms them into the required motion-vectors for the individual actuator drives. Any position and any orientation can be entered directly, and the specified target will be reached by a smooth vector motion. The pivot point then remains fixed relative to the platform (TABAKOVIĆ et al., 2013). 
INDEPENDENT JOURNAL OF MANAGEMENT \& PRODUCTION (IJM\&P)

http://www.ijmp.jor.br

v. 5, n. 3, June - September 2014

ISSN: 2236-269X

DOI: 10.14807/ijmp.v5i3.159

In addition to the coordinated output of the six hexapod axes, these new hexapod controllers provide two additional axes that can be used to operate rotary stages, linear stages or linear actuators. Some include a macro language for programming and storing command sequences. These controllers feature flexible interfaces, such as TCP/IP interface for remote, network and Internet connection.

New simulation tools are being incorporated for graphical configuration and simulation of hexapods to verify workspace requirements and loads. Such software provides full functionality for creation, modeling, simulation, rendering and playback of hexapod configurations to predict and avoid interference with possible obstacles in the workspace.

With the new design developments that hexapod systems are experiencing, manufacturers and researchers that have a need for extreme high resolutions and high accuracy can now capitalize on them for improvements within their workplace. Hexapod technology has advanced considerably in a few short years, now it is up to industry to embrace these new developments and put them to work to reduce their set-up and processing time, overall production cycle times, and ultimately reduced cost of operation.

\section{CONCLUSIONS}

The presented method manages to synthesize (in theory) the best option parameters for any desired parallel system. Moving mechanical systems parallel structures are solid, fast, and accurate. Between parallel systems (WANG et al., 2013) it is to be noticed Stewart platforms, as the oldest systems, fast, solid and precise.

The work outlines a few main elements of Stewart platforms. Begin with the geometry platform, kinematic elements of it, and presented then and a few items of dynamics. Dynamic primary element on it means the determination mechanism kinetic energy of the entire Stewart platforms. It is then in a record tail cinematic mobile by a method dot matrix of rotation.

If a structural mottoelement consists of two moving elements which translates relative, drive train and especially dynamic it is more convenient to represent the mottoelement as a single moving components. 
We have thus seven moving parts (the six motoelements or feet to which is added mobile platform 7) and one fixed.

Proposed method (in this work) may determine kinematic parameters system position when required the co-ordinates of the endeffector $\mathrm{S}$.

This is clearly a reverse motion (an inverse kinematics) (LIN et al., 2013).

Method is direct, simple, quick and accurate.

Information display method presented is much simpler and more direct in comparison with methods already known.

\section{REFERENCES}

CAO, W.; DING, H.; BIN, ZI; ZIMING, CHEN (2013). New Structural Representation and Digital-Analysis Platform for Symmetrical Parallel Mechanisms, International Journal of Advanced Robotic Systems, Sumeet S Aphale (Ed.), ISBN: 1729-8806, InTech, DOI: 10.5772/56380. Available from:

http://www.intechopen.com/journals/international_journal_of_advanced_robotic_syst ems/new-structural-representation-and-digital-analysis-platform-for-symmetricalparallel-mechanisms.

MELO, L. F.; ALVES, S. F. R.; ROSÁRIO, J. M. (2012) Mobile Robot Navigation Modelling, Control and Applications, in International Review on Modelling and Simulations, April 2012, v. 5, n. 2B, p. 1059-1068. Available from: http://www.praiseworthyprize.com/IREMOS-latest/IREMOS_vol_5_n_2.html.

LEE, B. J. (2013). Geometrical Derivation of Differential Kinematics to Calibrate Model Parameters of Flexible Manipulator, International Journal of Advanced Robotic Systems, Jaime Gallardo-Alvarado, Ramon Rodrıguez-Castro (Ed.), ISBN: 1729-8806, InTech, DOI: 10.5772/55592. Available from:

http://www.intechopen.com/journals/international_journal_of_advanced_robotic_syst ems/geometrical-derivation-of-differential-kinematics-to-calibrate-mode--parametersof-flexible-manipula.

LIN, W.; BING LI; XIAOJUN Y.; DAN Z. (2013). Modelling and Control of Inverse Dynamics for a 5-DOF Parallel Kinematic Polishing Machine, International Journal of Advanced Robotic Systems, Sumeet S Aphale (Ed.), ISBN: 1729-8806, InTech, DOI: $10.5772 / 54966$. Available from:

http://www.intechopen.com/journals/international_journal_of_advanced_robotic_syst ems/modelling-and-control-of-inverse-dynamics-for-a-5-dof-parallel-kinematicpolishing-machine. 
INDEPENDENT JOURNAL OF MANAGEMENT \& PRODUCTION (IJM\&P)

http://www.ijmp.jor.br

v. 5, n. 3, June - September 2014

ISSN: 2236-269X

DOI: 10.14807/ijmp.v5i3.159

GARCIA, E.; JIMENEZ, M. A.; SANTOS, P. G.; ARMADA, M. (2007) The evolution of robotics research, Robotics \& Automation Magazine, IEEE , v.14, n.1, p.90-103, March 2007. Available from:

http://ieeexplore.ieee.org/stamp/stamp.jsp?tp=\&arnumber=4141037\&isnumber=4141 014.

GARCIA, M. M.; GALLARDO, A. J.; CASTILLO C. E. (2013). Finding the Generalized Forces of a Series-Parallel Manipulator, IJARS, Jaime Gallardo-Alvarado, Ramon Rodrıguez-Castro (Ed.), ISBN: 1729-8806, InTech, DOI: 10.5772/53824. Available from:

http://www.intechopen.com/journals/international_journal_of_advanced_robotic_syst ems/finding-the-generalized-forces-of-a-series-parallel-manipulator.

HE, B.; WANG, Z.; LI, Q.; XIE, H.; SHEN, R. (2013). An Analytic Method for the Kinematics and Dynamics of a Multiple-Backbone Continuum Robot, IJARS, Patricia Melin (Ed.), ISBN: 1729-8806, InTech, DOI: 10.5772/54051. Available from: http://www.intechopen.com/journals/international_journal_of_advanced_robotic_syst ems/an-analytic-method-for-the-kinematics-and-dynamics-of-a-multiple-backbonecontinuum-robot.

LIU, H.; ZHOU, W.; LAI, X.; ZHU, S. (2013). An Efficient Inverse Kinematic Algorithm for a PUMA560-Structured Robot Manipulator, IJARS, Jaime Gallardo-Alvarado, Ramon Rodrıguez-Castro (Ed.), ISBN: 1729-8806, InTech, DOI: 10.5772/56403. Available from:

http://www.intechopen.com/journals/international_journal_of_advanced_robotic_syst ems/an-efficient-inverse-kinematic-algorithm-for-a-puma560-structured-robotmanipulator.

PADULA, F.; PERDEREAU, V., (2013). An On-Line Path Planner for Industrial Manipulators, International Journal of Advanced Robotic Systems, Antonio Visioli (Ed.), ISBN: 1729-8806, InTech, DOI: 10.5772/55063. Available from:

http://www.intechopen.com/journals/international_journal_of_advanced_robotic_syst ems/an-on-line-path-planner-for-industrial-manipulators.

PERUMAAL, S.; JAWAHAR, N., (2013). Automated Trajectory Planner of Industrial Robot for Pick-and-Place Task, IJARS, Antonio Visioli (Ed.), ISBN: 1729-8806, InTech, DOI: 10.5772/53940. Available from:

http://www.intechopen.com/journals/international_journal_of_advanced_robotic_syst ems/automated-trajectory-planner-of-industrial-robot-for-pick-and-place-task.

PETRESCU, F. I., PETRESCU, R. V. (2013) Cinematics of the 3R Dyad, in journal Engevista, v. 15, n. 2, p. 118-124, August 2013, ISSN 1415-7314. Available from: http://www.uff.br/engevista/seer/index.php/engevista/article/view/376.

PETRESCU, F. I., PETRESCU, R. V. (2012) Kinematics of the Planar Quadrilateral Mechanism, in journal Engevista, v. 14, n. 3, p. 345-348, December 2012, ISSN 1415-7314. Available from:

http://www.uff.br/engevista/seer/index.php/engevista/article/view/377. 
INDEPENDENT JOURNAL OF MANAGEMENT \& PRODUCTION (IJM\&P)

http://www.ijmp.jor.br

v. 5, n. 3, June - September 2014

ISSN: 2236-269X

DOI: 10.14807/ijmp.v5i3.159

PETRESCU, F. I., PETRESCU, R. V. (2012) Mecatronica - Sisteme Seriale si

Paralele, Create Space publisher, USA, March 2012, ISBN 978-1-4750-6613-5, 128 pages, Romanian edition.

PETRESCU, F. I, PETRESCU, R. V (2011) Mechanical Systems, Serial and Parallel - Course (in romanian), LULU Publisher, London, UK, February 2011, 124 pages, ISBN 978-1-4466-0039-9, Romanian edition.

PETRESCU, F. I., GRECU, B., COMANESCU, A., PETRESCU, R. V. (2009) Some Mechanical Design Elements. In the 3rd International Conference on Computational Mechanics and Virtual Engineering, COMEC 2009, Braşov, October 2009, ISBN 978-973-598-572-1, Edit. UTB, p. 520-525.

REDDY, P.; SHIHABUDHEEN K. V.; JACOB, J. (2012) Precise Non Linear Modeling of Flexible Link Flexible Joint Manipulator, in International Review on Modelling and Simulations, June 2012, v. 5, n. 3B, p. 1368-1374. Available from: http://www.praiseworthyprize.com//REMOS-latest//REMOS_vol_5_n_3.html.

TABAKOVIĆ, S.; MILAN, Z.; RATKO, G.; ŽIVKOVIĆ, A. (2013).

Program Suite for Conceptual Designing of Parallel Mechanism-Based Robots and Machine Tools, International Journal of Advanced Robotic Systems, Sumeet S Aphale (Ed.), ISBN: 1729-8806, InTech, DOI: 10.5772/56633. Available from: http://www.intechopen.com/journals/international_journal_of_advanced_robotic_syst ems/program-suite-for-conceptual-designing-of-parallel-mechanism-based-robotsand-machine-tools.

TANG, X.; SUN, D.; SHAO, Z., (2013). The Structure and Dimensional Design of a Reconfigurable PKM, IJARS, Sumeet S Aphale (Ed.), ISBN: 1729-8806, InTech, DOI: 10.5772/54696. Available from:

http://www.intechopen.com/journals/international_journal_of_advanced_robotic_syst ems/the-structure-and-dimensional-design-of-a-reconfigurable-pkm.

TONG, G.; GU, J.; XIE, W. (2013). Virtual Entity-Based Rapid Prototype for Design and Simulation of Humanoid Robots, International Journal of Advanced Robotic Systems, Guangming Xie (Ed.), ISBN: 1729-8806, InTech, DOI: 10.5772/55936. Available from:

http://www.intechopen.com/journals/international_journal_of_advanced_robotic_syst ems/virtual-entity-based-rapid-prototype-for-design-and-simulation-of-humanoidrobots.

WANG, K.; LUO, M.; MEI, T.; ZHAO, J.; CAO, Y., (2013). Dynamics Analysis of a Three-DOF Planar Serial-Parallel Mechanism for Active Dynamic Balancing with Respect to a Given Trajectory, International Journal of Advanced Robotic Systems, Sumeet S Aphale (Ed.), ISBN: 1729-8806, InTech, DOI: 10.5772/54201. Available from:

http://www.intechopen.com/journals/international_journal_of_advanced_robotic_syst ems/dynamics-analysis-of-a-three-dof-planar-serial-parallel-mechanism-for-activedynamic-balancing-with-. 